\title{
PENDIDIKAN ISLAM DI MALAYSIA: Jenis, Jenjang, Kebijakan, dan Tujuan Pendidikan
}

\author{
Andi Aslindah \\ Pesantren Manbaul Ulum Maros \\ Jalan Poros Leang-leang Maros, Sulawesi Selatan \\ Email: dede.pindang@gmail.com
}

\begin{abstract}
Abstrak:
Tujuan Pendidikan Islam adalah membentuk kepribadian muslim yang mengembangkan potensi spiritual, fisik, emosi, intelektual dan sosial. Tujuan tersebut bukan hanya menghasilkan manusia yang baik tapi juga mencakup pembentukan manusia yang bersifat religious dan duniawi. Lebih lanjut, pendidikan harus didasarkan pada pengajaran Islam yang bertujuan menghasilkan manusia yang berkualitas yang dapat memenuhi kebutuhan dunia dan kehidupan di akhirat. Fokus utama dari penelitian ini adalah perkembangan pendidikan Islam di Malaysia, jenis dan tingkatan pendidikan, dan kebijakan pendidikan.
\end{abstract}

\begin{abstract}
:
The purpose of Islam education is to form Muslim personal that develop spiritual, physical, emotional intellectual and social potensials. It does not only produces good citizens but also covers the formation of a complete human capital in terms of religious and worldly life. In addition, The goal of Islamic education not only to produce good person but also the persons who that can meet the needs of the world and life in the hereafter. The main focus of this article is about the development of Islamic Education in Malaysia include the type and level of education, and education policy.
\end{abstract}

\section{Kata kunci: \\ Education, Islamic Education, Malaysia, Education Policy}

PENDIDIKAN Islam dalam teori dan praktik selalu mengalami perkembangan. Hal ini disebabkan karena pendidikan Islam secara teoretik memiliki dasar dan sumber rujukan yang tidak hanya berasal dari nalar, melainkan juga berasal dari wahyu. Kombinasi nalar dan wahyu ini ideal, karena memadukan antara potensi akal manusia dan tuntunan firman Allah terkait dengan masalah pendidikan. Kombinasi ini menjadi ciri khas pendidikan Islam yang tidak dimiliki oleh konsep pendidikan pada umumnya yang hanya mengandalkan kekuatan akal dan budaya manusia. ${ }^{1}$

Ahmad Supardi memaknai pendidikan Islam sebagai pendidikan yang berdasar pada ajaran Islam atau tuntunan agama Islam dalam usaha membina dan membentuk pribadi muslim yang bertakwa kepada Allah, cinta kasih kepada orang tua dan sesama, juga kepada tanah airnya sebagai karunia yang diberikan oleh Allah swt. ${ }^{2}$ Pendidikan adalah elemen penting dalam proses tumbuh besar dan kematangan seseorang yang dapat melahirkan generasi berguna serta berakhlak mulia. Oleh karena itu, sistem pendidikan yang baik sangat penting untuk menanamkan pribadi yang mulia dalam diri individu. 
Implementasi sistem pendidikan Islam di berbagai negara yang berpenduduk muslim mempunyai corak serta sistem yang terkadang memiliki perbedaan antara yang satu dengan yang lainnya, ${ }^{3}$ bukan hanya terletak pada seberapa banyak penganut Islam di negara itu, melainkan juga ditentukan oleh sistem pendidikan yang dijalankan di negara tersebut.

Di Malaysia, yang masyarakatnya mayoritas Islam, tampak kelihatan sangat heterogen terutama bila dilihat dari segi etnis, suku, dan ras mereka, sehingga di Malaysia dapat dijumpai sejumlah kelompok masyarakat muslim Indo-Melayu, bahkan suku Bugis dan Makassar. Hal tersebut menimbulkan nuansa yang berbeda dengan negara yang relatif berimbang antara setiap pemeluknya, misalnya negara tersebut memiliki pluralitas agama, tentu sangat berpengaruh terhadap corak dan sistem pendidikannya.

Malaysia merupakan salah satu negara yang memiliki posisi yang cukup penting di dunia Islam karena kiprah keislamannya. Berbagai proses islamisasi di negeri jiran ini tentu tidak terjadi begitu saja, melainkan didahului oleh peran pedagang muslim, perjuangan para mubalig, serta penanaman niai-nilai Islam melalui pendidikan. Namun, penulis hanya memetakan pendidikan Islam di Malaysia ke dalam tiga garis besar yaitu: gambaran pendidikan Islam di Malaysia, jenis dan jenjang, serta kebijakan dan tujuan pendidikan.

Untuk melihat sejarah perkembangan pendidikan Islam di Malaysia, maka pembahasan ini akan difokuskan pada: 1) gambaran pendidikan Islam di Malaysia; 2) jenis dan jenjang pendidikan Islam di Malaysia; dan 3) implementasi kebijakan dan tujuan pendidikan Islam di Malaysia.

\section{GAMBARAN PENDIDIKAN ISLAM DI MALAYSIA}

Malaysia adalah salah satu negara anggota ASEAN yang memproklamirkan kemerdekaannya pada tanggal 31 Agustus 1957 dari tangan Inggris dengan nama Persekutuan Tanah Melayu. Kemudian pada tahun 1963 negara federal diubah menjadi Malaysia, termasuk di dalamnya Sabah, Serawak, dan Singapura. Dua tahun berikutnya, Singapura terpisah dari Malaysia, dan Malaysia memiliki 13 negara bagian yang disebut negeri dan tiga wilayah persekutuan. Wilayah persekutuan diperintah secara langsung oleh pemerintah federal di bawah kekuasaan perdana menteri. Ke tiga belas negara tersebut adalah: Kelantan, Trengganu, Pahang, Johor, Malaka, Negeri Sembilan, Selangor, Perak, Kedah, Perlis, Pulau Pinang, Sabah, dan Serawak. Sementara tiga wilayah persekutuan adalah: Kuala Lumpur, Labuan, dan Putrajaya. Tujuan dibentuknya wilayah persekutuan adalah untuk menjadi pusat pemerintahan Malaysia. Dari ketiga wilayah persekutuan ini, Kuala Lumpur merupakan ibu kota persekutuan, Labuan merupakan pusat perniagaan dan kewangan antarabangsa (IBFC), dan Putrajaya merupakan pusat pemerintahan persekutuan. Kepala negara Malaysia adalah seorang raja dengan gelar "Yang Dipertuan Agung". Pemerintahan berada di tangan perdana menteri yang berhak membentuk kabinet. ${ }^{4}$ 
Seperti halnya di Indonesia, pendidikan Islam di Malaysia tidak dapat dipastikan secara tepat kapan dimulai, tetapi perkara ini dapat dilihat pada latar belakang sejarah kedatangan agama Islam di negara ini dan aktivitas serta kegiatan pendidikan yang berjalan pada waktu tersebut. Kedatangan Islam dan proses islamisasi berlangsung melalui jalur perdagangan atas peranan para pedagang muslim dan mubalig dari Arab dan Gujarat, para dai setempat dan penguasa Islam. ${ }^{5}$ Malaysia pun menjadi basis utama penyebaran Islam ke Kepulauan Hindia Timur. ${ }^{6}$ Sejak merdeka tahun 1957, ilmu pengetahuan agama Islam telah dijadikan sebagai kurikulum pendidikan nasional Malaysia dan diberikan selama 120 menit per minggunya. Akan tetapi, pemerintah tidak melakukan penekanan atau lulus ujian ilmu pengetahuan agama Islam, sehingga pelajaran ini tidak mendapat perhatian serius dari siswa pada masa tersebut. ${ }^{7}$

Sejak tahun 1980-an, Islam di Malaysia mengalami kebangkitan yang ditandai dengan semaraknya kegiatan dakwah dan kajian Islam oleh kaum intelektual. ${ }^{8}$ Perkembangan masjid dan surau di Malaysia mencerminkan semaraknya aktivitas umat Islam. Misalnya, Bandar Baru Bangi merupakan daerah yang memiliki masjid dan surau dengan perkembangan yang sangat pesat. Masjid-masjid tersebut, bukan saja untuk melaksanakan salat, melainkan juga digunakan sebagai lembaga pendidikan Islam. Surau an-Nur di Bandar Baru Bangi misalnya, merupakan tempat kajian alQur'an dan tafsir baik laki-laki maupun perempuan, terkadang diadakan tahlil serta perbincangan keagamaan yang terjadwal secara sistematis tentang segala hal yang berkaitan dengan masalah spiritual dan problem masyarakat masa kini. ${ }^{9}$

Pendidikan di Malaysia pada dasarnya mengadopsi sistem dari negara Inggris sebab Malaysia merupakan salah satu negara bekas jajahan Inggris. Hal ini yang menyebabkan Malaysia maju di bidang pendidikan, di mana negara Inggris sangat memerhatikan pendidikan untuk negeri jajahannya. Ini berbeda dengan Indonesia yang merupakan bekas jajahan Beanda. Belanda hanya ingin mengerut kekayaan negara jajahannya tanpa memberikan pendidikan yang intensif. Akibatnya negaranegara yang dijajah oleh Belanda cenderung terbelakang dalam bidang pendidikan. Negara Malaysia memiliki keinginan kuat untuk menjadikan pendidikannya itu go international. Buktinya hal itu dituangkan dalam rumusan misi utama Kementerian Pelajaran Malaysia, yang berbunyi, "Mewujudkan sistem pendidikan bertaraf dunia untuk merealisasikan potensi sepenuhnya setiap individu, di samping memenuhi aspirasi masyarakat Malaysia."10

Tiga rahasia keberhasilan pendidikan di Malaysia yaitu: 1) mau belajar dari negara-negara lain yang lebih dulu maju; 2) mau mengalokasi anggaran pendidikan dalam jumlah yang cukup memadai; 3) membuat perencanaan jangka panjang yang sistematis dan dijalankan secara konsekuen.11

Pemimpin negara Malaysia meyakini hanya dengan pendidikan yang bermutu maka bangsa Malaysia bisa menjadi bangsa yang terhormat di mata bangsa-bangsa yang lainnya. Secara konsekuen, mereka menjalankan perencanaan jangka panjang yang telah disusun dan diputuskannya. Menghilangkan arogansi kinerja pendidikan 
di Malaysia yang sangat memadai tersebut terbukti telah membawa kemajuan yang sangat berarti bagi bangsa Malaysia dan dalam banyak hal telah meninggalkan negara-negara yang dulu pernah dianggap sebagai gurunya.

Dari tatanan aplikasi, pemerintah Malaysia menyediakan sarana dan prasarana belajar yang sangat baik, baik dari segi sumber ilmu yang berasal dari buku-buku dengan cara menyediakan perpustakaan yang lengkap maupun beasiswa yang diberikan kepada orang yang masih belajar.

Pemerintah Malaysia mempunyai perhatian yang besar dalam meningkatkan kualitas dan mutu perguruan tinggi demi memajukan pendidikan Islam. Tidak semua IPTA dan IPTS di Malaysia membuka Islamic Studies. Beberapa Perguruan tinggi yang membuka program Islamic Studies adalah: Internasional Islamic University of Malaysia (IIUM), University of Malaya (UM), University Kebangsaan Malaysia (UKM), Univerisity Utara Malaysia (UUM), Univerisity Pendidikan Sultan Idris (UPSI), University Sains Malaysia (USM), dan Kolej University Islam Selangor (KUIS).

University Malaysia (UM) adalah universitas tertua di Malaysia. Berdiri pada tanggal 8 Oktober 1948 ketika King Edward VII College of Medicine dan Raffles College bergabung menjadi University Malaysia di Singapura. Sedangkan University Kebangsaan Malaysia (UKM) adalah universitas yang didirikan setelah UM. Ia berdiri pada tanggal 18 Mei 1970 dan bertempat di Lembah Pantai Kuala Lumpur. Adapun International Islamic University of Malaysia (IIUM) yang biasa disebut University Islam Antarbangsa Malaysia (UIAM) merupakan hasil kerja sama antara kerajaan Malaysia dan Organitation of the Islamic Conference (OIC). ${ }^{12}$

Ketiga institusi tersebut membuka fakultas atau akademi studi Islam dan menawarkan hampir semua program studi yang ada dalam studi Islam, baik untuk jenjang S1, S2, maupun S3 seperti Fikih dan Usul Fikih, Alquran dan Sunah Studies, Communication, English Literature and Linguistic. Ketiga universitas tersebut menggunakan sistem semester dalam kegiatan belajar mengajar. Dosen-dosen yang mengajar adalah dosen-dosen lulusan universitas-universitas lokal Malaysia dan lulusan luar negeri, baik Timur Tengah maupun Barat. ${ }^{13}$

Sedikit dapat diketahui bagaimana gambaran agama Islam di Malaysia dan bagaimana pendidikan Islam di Malaysia. Walaupun terdiri dari berbagai etnis dan suku bangsa yang bercampur baur, tetapi Malaysia mampu menjadikan Islam menjadi agama yang resmi dan menjalankan pendidikan Islam dengan baik. Bahkan hampir yang kelihatan dari Malaysia adalah nuansa keislamannya yang kental. Meskipun Malaysia dianggap sebagai sebuah negara muslim yang menyatakan Islam sebagai agama resmi, namun sekelompok minoritas penduduknya adalah non muslim.

\section{JENIS DAN JENJANG PENDIDIKAN ISLAM DI MALAYSIA}

Bukti adanya pondok yang pertama di tanah Melayu berada di Trengganu, yang telah lama dikenal sebagai pusat studi Islam tradisional. Sistem pondok didirikan pada tahun 1820 oleh Haji Abdul Samad bin Faqih Haji Abdullah atau lebih 
dikenal dengan gelar Tok Pulai Condong. Setelah itu muncullah tokoh-tokoh ulama yang giat mengembangkan ilmu, baik melalui pendidikan di pondok-pondok maupun melalui karya-karya yang dihasilkan. ${ }^{14}$ Kini sekolah pondok, madrasah, dan sekolah agama Islam lain masih ada di Malaysia, terutama di kawasan Bandar dan kebanyakan dari alumninya, melanjutkan studinya ke negara lain seperti Pakistan dan Mesir. ${ }^{15}$

Penerapan kurikulum pendidikan Islam di Malaysia tidak berbeda jauh dengan pendidikan Islam di Indonesia, yaitu kurikulum pendidikan Islam yang mengandung dua kurikulum inti sebagai kerangka dasar operasional pengembangan kurikulum, yaitu: tauhid sebagai unsur pokok yang tidak dapat diubah dan perintah membaca ayat-ayat Alquran. ${ }^{16}$

Prinsip umum yang menjadi dasar kurikulum pendidikan Islam di Malaysia adalah:

- Adanya pertautan yang sempurna dengan agama, termasuk ajaran-ajaran dan nilai-nilainya.

- Prinsip menyeluruh (universal) pada tujuan-tujuan dan kandungan-kandungan kurikulum.

- Keseimbangan yang relatif antara tujuan dan kandungan-kandungan kurikulum.

- Perkaitan dengan bakat, minat, kemampuan-kemampuan dan kebutuhan pelajar dan juga dengan alam sekitar, fisik, dan sosial tempat pelajar itu hidup berinteraksi.

- Pemeliharaan atas perbedaan-perbedaan individu di antara pelajar dalam bakat-bakat, minat, kemampuan, kebutuhan, dan perbedaan lingkungan masyarakat.

- Penyesuaian dengan perkembangan dan perubahan yang berlaku dalam kehidupan.

- Pertautan antara mata pelajaran, pengalaman, dan aktivitas yang terkandung dalam kurikulum, dan pertautan antara kandungan kurikulum dengan kebutuhan murid dan kebutuhan masyarakat tempat murid itu tinggal. ${ }^{17}$

\section{Jenis Sekolah}

\section{Sekolah Kebangsaan}

Bahasa Malaysia digunakan sebagai bahasa pengantar di sekolah kebangsaan. Sekolah kebangsaan merupakan salah satu jenis sekolah rendah.

\section{Sekolah Kluster}

Suatu nama yang diberikan kepada sekolah yang dikenal cemerlang, baik dari aspek manajemennya maupun dari outputnya.

\section{Sekolah Wawasan}

Sekolah Wawasan menggunakan bahasa Ibu, sekolah ini berorientasi untuk mengembangkan keakraban antar kaum dalam berinteraksi. 


\section{Sekolah Agama Islam}

Sekolah pondok, madrasah, dan sekolah agama Islam lain merupakan bentuk sekolah asal di Malaysia.

\section{Sekolah Teknik dan Vokasional}

Sekolah ini memberi peluang kepada murid yang mempunyai keahlian dalam pendidikan sains dan teknologi untuk memenuhi tenaga kerja dalam bidang industri negara.

\section{Sekolah Berasrama Penuh}

Maktab Rendah Sains MARA (MRSM) dan Sekolah Berasrama Penuh atau Residential School juga dikenal sebagai sekolah-sekolah sains (science schools). Sekolahsekolah ini digunakan untuk memenuhi kebutuhan calon-calon elit Malaysia tetapi kemudian diperluas sebagai sekolah untuk menjaga Malaysia dengan cara menerima siswa dengan kemampuan akademik dan bakat-bakat olah raga serta kepemimpinan yang menonjol. Sekolah tersebut dijadikan sebagai model setelah Sekolah Asrama Inggris (British Boarding School). 18

\section{Jenjang Pendidikan}

\section{Prapendidikan Dasar}

Pendidikan di Malaysia dimulai dari pendidikan prasekolah yang disediakan oleh beberapa instansi pemerintah, badan swasta, dan lembaga-lembaga sukarela dan diikuti oleh anak didik berusia 4-6 tahun.

\section{Pendidikan Dasar}

Pendidikan dasar adalah wajib bagi semua anak-anak antara usia 7 dan 12.

\section{Pendidikan Menengah Pertama (Form I-III)}

Pendidikan menengah terbagi menjadi 2 siklus: menengah bawah, berlangsung 3 tahun yang disebut Form I-III, dan menengah atas, berlangsung 2 tahun yang disebut Form IV-V. Siswa sekolah dasar nasional langsung melanjutkan ke Form I. Adapun siswa dari sekolah tipe-nasional (Cina dan Tamil) mengikuti kelas transisi 1 tahun untuk mendapatkan bekal bahasa Melayu yang memadai, kecuali bagi siswa yang mendapatkan nilai yang memuaskan pada Tes Penilaian Primer dapat langsung mengikuti Form I.

Di akhir tahun pendidikan menengah pertama, siswa menjalani Ujian Penilaian Menengah Pertama (Lower Secondary Assessment Examination). ${ }^{19}$

\section{Pendidikan Menengah Atas (Form IV-V)}

Pada tingkat menengah atas, siswa dapat memilih salah satu di antara dua program yang ditawarkan: akademis dan teknik (kejuruan). Di akhir tahun, pendidikan siswa di bidang akademi menjalani ujian Malaysia Certificate of Education (MCE) yaitu sertifikat pendidikan Malaysia. 


\section{Pendidikan Pasca Pendidikan Menengah}

Setelah menyelesaikan pendidikan menengah, siswa dapat memilih untuk mengejar 1 sampai 2 tahun pendidikan pasca pendidikan menengah untuk mendapatkan Form VI dan pendidikan matrikulasi untuk persiapan masuk universitas. Pendidikan matrikulasi dipersiapkan untuk memenuhi persyaratan masuk khusus dari universitas tertentu. Adapun Form VI ditujukan untuk memenuhi persyaratan dari semua universitas.

\section{Pendidikan Tinggi}

Siswa yang telah menyelesaikan pendidikan menengah, mempersiapkan diri untuk menghadapi ujian sertifikasi Sekolah Tinggi Malaysia (di Indonesia dikenal sebagai SPMB atau UMPTN) yang diselenggarakan oleh Dewan Ujian Malaysia. Lembaga pendidikan tinggi mencakup universitas, akademi, dan politeknik. Program yang ditawarkan beragam, mulai sertifikat, diploma, hingga degree levels. Pada tingkat sarjana pendidikan ditempuh selama 3-4 tahun. ${ }^{20}$

\section{IMPLEMENTASI KEBIJAKAN DAN TUJUAN PENDIDIKAN ISLAM DI MALAYSIA}

\section{Kebijakan Pendidikan}

Ketika Mahathir Muhammad menjabat sebagai Menteri Pendidikan, kebijakan dan program keislaman di bidang pendidikan terlihat lebih awal mendapat perhatian dibanding bidang lainnya. Beliau merupakan sosok yang dikenal banyak berperan dan memberikan kontribusi bagi upaya islamisasi di Malaysia. Di awal karirnya sebagai Menteri Pendidikan Malaysia tahun 1974, Mahathir mengawali langkahnya dengan meninjau ulang sistem pengajaran agama Islam yang dipandangnya tidak efektif dan tidak sesuai dengan perkembangan dan kebutuhan zaman. Segera setelah itu, ia mengadakan pengkajian kembali tentang pendidikan agama Islam dan sistem pengajarannya serta membentuk dewan penasihat untuk pendidikan agama Islam. Pembentukan dewan penasihat ini dimaksudkan untuk menggerakkan agar Islam menjadi relevan dengan kebutuhan modernisasi masyarakat muslim Malaysia dan agar gerakan ini dapat dilaksanakan secara koor-dinatif dan sistematis. ${ }^{21}$

Pada tahun 1975, Kementerian Pendidikan mengeluarkan dana yang cukup besar untuk memperbaiki pelaksanaan pelatihan guru-guru agama Islam. Pada tahun berikutnya, pemerintah mengumumkan pengambilalihan atas sepuluh sekolah Islam terbaik di negara itu guna memperbaiki manajemen sekolah tersebut serta meningkatkan kinerja para guru dan pegawainya untuk dijadikan sebagai sekolah model. Pada tahun 1979, pemerintah mendeklarasikan pendirian Pusat Penelitian Islam Asia Tenggara. Pada tahun yang sama, pengetahuan agama Islam ditetapkan sebagai materi ujian di tingkat Sijil Pelajaran Malaysia (SPM). Setahun berikutnya pemerintah mendirikan yang pertama kali Maktab Perguruan Islam (Islamic Teacher's College) yang dari sana murid-murid berpotensi akan dikirim ke Mesir, Pakistan, dan Indonesia untuk melanjutkan studi mereka. ${ }^{22}$ 
Adapun kebijakan lainnya terhadap pendidikan Islam di Malaysia antara lain:

- Sejak merdeka pada tahun 1957, ilmu pengetahuan agama Islam telah dijadikan sebagai kurikulum pendidikan nasional Malaysia.

- Pada tahun 1975, berbagai langkah penting untuk memperkuat pendidikan Islam ditempuh oleh Departemen Pendidikan.

- Pada tahun 1982, Perdana Menteri Mahathir Muhammad mengambil keputusan untuk menjalankan kebijakan penanaman nilai-nilai Islam di pemerintahan.

- Tahun 1983, Departemen Pendidikan menyatakan bahwa nilai-nilai moral akan diajarkan kepada pelajar nonmuslim, sementara ilmu pengetahuan agama akan diajarkan kepada para pelajar muslim. ${ }^{23}$

\section{Tujuan Pendidikan}

Untuk setiap negara yang sudah mencapai kemerdekaan, salah satu aspek penting yang sangat prioritas untuk menuju ke arah negara yang maju dan berkembang dari aspek politik, ekonomi, dan sosial adalah penekanan terhadap pelaksanaan sistem pendidikan negara. Sistem pendidikan yang dilaksanakan di suatu negara sangat penting, bukan saja karena fungsi kebijakan dan sosialisasinya yaitu di mana anak-anak dididik untuk menjadi insan yang berhasil dan mengenali budaya serta alam sekeliling, melainkan bisa digunakan sebagai wadah untuk menyampaikan ideologi nasional kepada masyarakat yaitu melalui penerapan tentang pemahaman dan nilai-nilai positif untuk persatuan kaum di kalangan para pelajar. Pada dasarnya, tujuan pendidikan Islam di semua negara itu sama, yaitu harus selaras dengan tujuan penciptaan manusia di dunia. Sebagaimana kita ketahui bahwa dalam Islam tujuan penciptaan manusia adalah untuk mengabdikan diri kepada Allah.

Hal ini dapat dilihat dalam firman Allah QS. al-Zariyat/51: 56.

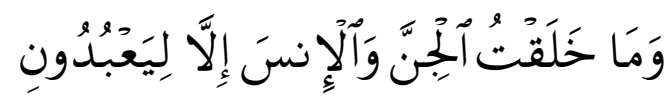

Dan tidaklah aku menciptakan jin dan manusia melainkan agar mereka mengabdi (beribadah) kepada-Ku. ${ }^{24}$

Untuk itu, pendidikan Islam bertujuan untuk menciptakan manusia yang siap menghambakan diri kepada Allah dengan melakukan segala perintah-Nya dan menjauhi segala larangan-Nya.

Secara umum, pendidikan di Malaysia bertujuan mengembangkan potensi individu secara menyeluruh dan terpadu untuk mewujudkan insan yang seimbang dan harmonis dari segi intelek, rohani, emosi, dan jasmani, berdasarkan kepercayaan dan kepatuhan kepada Tuhan. Tujuan ini dimaksudkan agar dapat melahirkan rakyat Malaysia yang berilmu pengetahuan, berketerampilan, berakhlak mulia, dan bertanggung jawab terhadap masyarakat dan negara. ${ }^{25}$

Dapat dipahami ada banyak faktor pendukung untuk menjadikan pendidikan Islam di Malaysia lebih maju. Di antaranya, dengan adanya perubahan kebijakankebijakan pendidikan Islam yang berarti akan menjadikan pendidikan Islam di 
Malaysia secara otomatis terimplementasi dengan baik.

\section{SIMPULAN}

Pendidikan Islam di Malaysia sudah dapat dikatakan maju, karena pemerintah sangat menekankan pendidikan Islam dan nilai moral sangat diperlukan untuk pembangunan masyarakatnya. Hal ini dibuktikan dengan adanya beberapa universitas di Malaysia yang membuka program Islamic Studies seperti Internasional Islamic University of Malaysia (IIUM), University Malaya (UM), University Kebangsaan Malaysia (UKM), University Sains Malaysia (USM), Kolej University Islam Selangor (KUIS), dan lain sebagainya.

Kebijakan-kebijakan pendidikan Islam di Malaysia antara lain, sejak merdeka pada tahun 1957, ilmu pengetahuan agama Islam telah dimasukkan dalam kurikulum pendidikan nasional Malaysia. Tahun 1975, berbagai langkah penting untuk memperkuat pendidikan Islam ditempuh oleh Departemen Pendidikan. Tahun 1982, Perdana Menteri Mahathir Muhammad mengambil keputusan untuk menjalankan kebijakan penanaman nilai-nilai Islam di pemerintahan. Tahun 1983, Departemen Pendidikan menyatakan bahwa nilai-nilai moral akan diajarkan kepada pelajar non-muslim, sementara ilmu pengetahuan agama akan diajarkan kepada para pelajar muslim. Pendidikan di Malaysia bertujuan mengembangkan potensi individu secara menyeluruh dan terpadu untuk mewujudkan insan yang seimbang dan harmonis dari segi intelektual, rohani, emosi, dan jasmani, berdasarkan kepercayaan dan kepatuhan kepada Tuhan. Tujuan ini dimaksudkan agar dapat melahirkan rakyat Malaysia yang berilmu pengetahuan, berketerampilan, berakhlak mulia, dan bertanggung jawab terhadap masyarakat dan negara.

Jenis dan jenjang pendidikan Islam di Malaysia yaitu jenis pendidikannya terdiri atas sekolah pondok, sekolah madrasah, dan sekolah agama Islam lain. Adapun jenis lembaga pendidikan umum seperti Sekolah Kebangsaan, Sekolah Kluster, Sekolah Jenis Kebangsaan, dan lain sebagainya. Jenjang pendidikannya yaitu Prapendidikan Dasar, Pendidikan Dasar, Pendidikan Menengah Pertama, Pendidikan Menengah Atas, Pendidikan Pascapendidikan Menengah, dan Pendidikan Tinggi

\section{CATATAN AKHIR}

1. Abd. Rachman Assegaf, Aliran Pemikiran Pendidikan Islam: Hadharah Keilmuan Tokoh Klasik Sampai Modern, Cet. II; Jakarta: Rajawali Pers, 2013, h. ix.

2. Ahmad Supardi, Sejarah dan Filsafat Pendidikan Islam, Bandung: Angkasa, 1992, h. 7.

3. Amrullah Ahmad etal., Dimensi Hukum Islam dalam Sistim Hukum Nasional, Cet. I; Jakarta: Gema Insani Press, 1996, h. xi.

4. Haidar Putra Daulay, Dinamika Pendidikan Islam di Asia Tenggara, Jakarta: Rineka Cipta, 2009, h. 53.

5. Abdul Rahman Haji Abdullah, Pemikiran Islam di Malaysia: Sejarah dan Aliran (Cet. I; Jakarta: Gema Insani Press, 1997), h. 14. 
6. Dewan Redaksi Ensiklopedia Islam, Ensiklopedia Islam, Jilid III, Cet. II; Jakarta: Ichtiar Baru Van Hoeve, 1994, h. 138.

7. Qasim A. Ibrahim dan Muhammad A. Saleh, Buku Pintar Sejarah Islam: Jejak Langkah Peradaban Islam dari Masa Nabi Hingga Masa Kini, Cet. II; Jakarta: Zaman, 2014, h. 1057.

8. Abd. Rachman Assegaf, Internasionalisasi Pendidikan: Sketsa Perbandingan Pendidikan di Negara-Negara Islam dan Barat, Yogyakarta: Gamma Media, 2003, h. 120.

9. Dewan Redaksi Ensiklopedia Islam, Ensiklopedia Islam Jilid III, h. 139.

10. Abd. Rachman Assegaf, Internasionalisasi Pendidikan: Sketsa Perbandingan Pendidikan di Negara-Negara Islam dan Barat, h. 121.

11. Supriyoko, Surat Kabar Harian "KEDAULATAN RAKYAT", Yogyakarta, Edisi 13 Desember 2000.

12. Master Tarbiyah, "Analisis Standar Mutu Pendidikan Indonesia dan Malaysia," Manajemen Pendidikan Islam, 14 Mei 2013, https://mastertarbiyah1982.wordpress.com/2013/05/14/analisis-standar-mutu-pendidikan-indonesia-dan-malaysia/(23 Oktober 2014).

13. STAIN Pekalongan, "Study Potret Sistem Pendidikan di Malaysia," Blog Komunitas Blogger Pekalongan, 24 April 2013,http://pekalonganbatiktv.blogspot.com/2013/04/makalahstudy-potret-sistem-pendidikan.html (24 Oktober 2014).

14. STAIN Pekalongan, "Study Potret Sistem Pendidikan di Malaysia," Blog Komunitas Blogger Pekalongan, 24 April 2013,http://pekalonganbatiktv.blogspot.com/2013/04/makalahstudy-potret-sistem-pendidikan.html (24 Oktober 2014).

15. Abdul Rahman Haji Abdullah, Pemikiran Islam di Malaysia: Sejarah dan Aliran, h. 34-35.

16. Zaiful Muzani, Pembangunan dan Kebangkitan Islam di Asia Tenggara(Cet. I; Jakarta: LP3ES, 1993), h. 292.

17. Adi Radili, "Dinamika Perkembangan Islam di Asia Tenggara," Blog Ar-Sembilan, http://arsembilan.blogspot.com/2013/10/makalah-dinamika-perkembangan.html Oktober 2014).

18. Ibid.

19. Almas Akbar, "Pendidikan Malaysia (Kajian Perbandingan Pendidikan)," Khazanah Keilmuan PAI, http://almasakbar45.blogspot.com/2012/04/bab-i-pendahuluan-latarbelakang.html (24 Oktober 2014).

20. Ibid.

21. Ibid.

22. Adi Radili, "Dinamika Perkembangan Islam di Asia Tenggara," Blog Ar-Sembilan, http://arsembilan.blogspot.com/2013/10/makalah-dinamika-perkembangan.html (23 Oktober 2014).

23. Ibid.

24. Abd. Rachman Assegaf, Internasionalisasi Pendidikan: Sketsa Perbandingan Pendidikan di Negara-Negara Islam dan Barat, h. 120.

25. Departemen Agama RI, Al-Qur'an dan Terjemahnya, Bandung: PT Syaamil Cipta Media, t.th., h. 524.

26. Abd. Rachman Assegaf, Internasionalisasi Pendidikan: Sketsa Perbandingan Pendidikan di Negara-Negara Islam dan Barat, h. 117. 


\section{DAFTAR PUSTAKA}

Abdullah, Amin. Filsafat Etika Islam: Antara Al-Gazali dan Kant. Cet. II; Bandung: Mizan, 2002.

Abdullah, Abdul Rahman Haji. Pemikiran Islam di Malaysia: Sejarah dan Aliran. Cet. I; Jakarta: Gema Insani Press, 1997.

Ahmad, Amrullah et.al.Dimensi Hukum Islam dalam Sistim Hukum Nasional. Cet. I; Jakarta: Gema Insani Press, 1996.

Akbar, Almas. "Pendidikan Malaysia (Kajian Perbandingan Pendidikan)," Khazanah Keilmuan PAI, http://almasakbar45.blogspot.com/2012/04/bab-i-pendahuluan-latar-belakang.html, 24 Oktober 2014.

Assegaf, Abd. Rachman. Aliran Pemikiran Pendidikan Islam: Hadharah Keilmuan Tokoh Klasik Sampai Modern. Cet. II; Jakarta: Rajawali Pers, 2013.

-------. Internasionalisasi Pendidikan: Sketsa Perbandingan Pendidikan di Negara-Negara Islam dan Barat. Yogyakarta: Gamma Media, 2003.

A. Ibrahim, Qasim dan Muhammad A. Saleh. Buku Pintar Sejarah Islam: Jejak Langkah Peradaban Islam dari Masa Nabi Hingga Masa Kini.Cet. II; Jakarta: Zaman, 2014.

Daulay, Haidar Putra. Dinamika Pendidikan Islam di Asia Tenggara. Jakarta: Rineka Cipta, 2009.

Departemen Agama RI. Al-Qur'an dan Terjemahnya. Bandung: PT. Syaamil Cipta Media, t.th.

Dewan Redaksi Ensiklopedia Islam. Ensiklopedia Islam Jilid III. Cet. II; Jakarta: Ichtiar Baru Van Hoeve, 1994.

Muzani, Zaiful.Pembangunan dan Kebangkitan Islam di Asia Tenggara. Cet. I; Jakarta: LP3ES, 1993.

Radili, Adi. "Dinamika Perkembangan Islam di Asia Tenggara." Blog Ar-Sembilan, http://arsembilan.blogspot.com/2013/10/makalah-dinamikaperkembangan.html, 23 Oktober 2014.

STAIN Pekalongan. "Study Potret Sistem Pendidikan di Malaysia." Blog Komunitas Blogger Pekalongan, 24 April 2013. http://pekalonganbatiktv.blogspot.com/2013/04/makalah-study-potretsistem-pendidikan.html, 24 Oktober 2014.

Supardi, Ahmad. Sejarah dan Filsafat Pendidikan Islam. Bandung: Angkasa, 1992.

Supriyoko, Surat Kabar Harian "KEDAULATAN RAKYAT", Yogyakarta, Edisi 13 Desember 2000. 